\title{
Acceptance of Nordic snack bars in children aged $8-1 \mid$ years
}

\author{
Anna Holmer', Helene Hausner ${ }^{2}$, Helene C. Reinbach², \\ Wender L. P. Bredie ${ }^{2}$ and Karin Wendin ${ }^{1,2,3 *}$
}

'Department of Sensory and Flavour Science, SIK - The Swedish Institute for Food and Biotechnology, Gothenburg, Sweden; ${ }^{2}$ Department of Food Science, University of Copenhagen, Frederiksberg, Denmark; ${ }^{3} \mathrm{SP}$ - The Technical Research Institute of Sweden, Lund, Sweden

Abstract

Background: A health promoting diet is suggested to be tailored to regional circumstances to preserve the cultural diversity in eating habits, as well as contribute to more environmentally friendly eating. It may influence consumer acceptance, however, if the components of the diet differs considerably from their habitual food.

Objective: This study aimed to investigate whether snack bars composed of Nordic ingredients were accepted by $8-11$ year-old Danish $(n=134)$ and Swedish $(n=109)$ children.

Design: A seven-point hedonic scale was used to measure the children's acceptance of five snack bars that varied in their composition of whole grains, berries and nuts. A preference rank ordering of the five bars was also performed.

Results: The results showed that samples that were rated highest in liking and were most preferred in both countries were a kamut/pumpkin bar and an oat/cranberry bar. The sample with the lowest rating that was also least preferred was a pumpernickel/sea buckthorn bar. Flavour was the most important determinant of overall liking followed by texture, odour and appearance.

Conclusions: Children's acceptances and preferences were highly influenced by the sensory characteristics of the bars, mainly flavour. In agreement with earlier studies, the novel food ingredients seemed to influence children's preferences. The Nordic snack bars may have a potential to be a snack option for Danish and Swedish school children, but repeated exposures to the products are recommended to increase children's acceptance.

Keywords: Nordic food; snacking; food preferences; food culture

Received: 6 October 2011; Revised: 24 March 2012; Accepted: 26 March 2012; Published: 24 April 2012

hildren's food choices are generally guided by their preferences, which are to some extent established early in life (1). Most of these preferences are learned via experiences (2). The choice of food, however, is a complex behaviour that is also influenced by factors related to the social context (3) School meals are organized differently in the Scandinavian countries (4). In Denmark, most children have a packed lunch provided by the parents, whereas meals are prepared at schools in Sweden. Danish and Swedish children are therefore exposed to different meal structures and meal items (5), which might influence their preferences for certain foods.

Nutritional studies of Danish and Swedish children's food habits have revealed unhealthy snacking patterns (6-9). These patterns continue into adulthood and contribute to an increased risk of obesity and chronic diseases
(10). To help children make better food choices, healthier snack options should be easily accessible. This agrees with the global strategy for diet, physical activity and health by the World Health Organization that recommend the food industry to develop and provide affordable, healthy choices to consumers (11). Few studies, though, have been conducted in order to examine children's sensory acceptance of novel snack foods. One study found that the most important factors for children to accept a new product were related to the product's appearance, taste and familiarity (12). Products that appeared to be too healthy were not desirable for the children, since eating a healthy product in front of friends could be embarrassing. Further, despite knowledge about healthy food options, children tend to choose products they prefer (13). Clearly, in order to develop more healthy food products that meet children's preferences there is 
still a need for a better understanding of children's food acceptance and preferences.

Whole grains, fruits, nuts and berries are recommended as a part of a healthy dietary intake because of their high nutritional value and health benefits such as reduced risk of coronary heart diseases $(14,15)$. A health promoting diet is suggested to be tailored to regional circumstances to preserve the cultural diversity in eating habits, as well as contribute to more environmentally eating (16). In the present study, snack bars that contained Nordic ingredients, such as whole grains, nuts and berries, were developed as part of an intervention project focusing on the health effect of eating foods grown in the Nordic countries (17). The concept of the New Nordic Diet in the OPUS project is to contribute to a new diet based on preferably local Nordic raw materials from sustainable production. If the components of the New Nordic Diet differ considerably from those of the children's habitual foods it may influence their acceptance.

The aim of this study was to investigate acceptance and determining factors for liking of snack bars composed of Nordic ingredients by $8-11$ year-old Danish and Swedish school children. We hypothesized that the variation of ingredients would influence the children's acceptances of the snack bars. We also expected that the differences in Danish and Swedish meal structures could affect children's preferences for the bars.

\section{Material and methods}

\section{Participants}

A total of 134 Danish (68 girls and 66 boys) and 109 Swedish (63 girls and 46 boys) children, aged 8-11, participated in the study. The children were recruited at primary schools. Exclusion criteria were food allergy or intolerance to any of the ingredients in the snack bars. Participation was voluntary and all the children were required to have parental consent.

\section{Experimental products}

Five Nordic snack bars varying in the composition of Nordic ingredients were produced for the study (Table 1). Some ingredients were novel to the children (e.g. sea buckthorn and kamut) while others were known (e.g. bilberries (Nordic blueberry) and oats). Sensory characteristics were evaluated by an expert panel $(n=5)$

Table 1. The ingredients and the approximate nutritional value of the five Nordic snack bars. Each sample was on average $8-9 \mathrm{~g}$

\begin{tabular}{|c|c|c|c|}
\hline Picture of product & Product & Ingredients & Nutritional contents / $100 \mathrm{~g}$ \\
\hline & Pumpernickel Sea Buckthorn & $\begin{array}{l}\text { Pumpernickel, sea buckthorn, rye, egg white, } \\
\text { fondant powder, sugar }\end{array}$ & $\begin{array}{l}\text { Energy: } 1202 \mathrm{~kJ} \\
\text { Carbohydrates: } 65 \mathrm{~g} \\
\text { Sugar: } 16 \mathrm{~g} \\
\text { Fat: I g }\end{array}$ \\
\hline & Kamut Pumpkin & $\begin{array}{l}\text { Kamut wheat, pumpkin seeds, hazelnuts, egg white, } \\
\text { sugar, honey, butter, fondant powder }\end{array}$ & $\begin{array}{l}\text { Energy: } 1543 \mathrm{~kJ} \\
\text { Carbohydrates: } 39 \mathrm{~g} \\
\text { Sugar: } 7 \mathrm{~g} \\
\text { Fat: } 20 \mathrm{~g}\end{array}$ \\
\hline & $\begin{array}{l}\text { Rye Bilberry } \\
\text { (Nordic blueberry) }\end{array}$ & $\begin{array}{l}\text { Rye flakes, bilberries, rye bread, egg white, honey, } \\
\text { sugar, fondant powder }\end{array}$ & $\begin{array}{l}\text { Energy: I448 kJ } \\
\text { Carbohydrates: } 78 \mathrm{~g} \\
\text { Sugar: } 12 \mathrm{~g} \\
\text { Fat: } 2 \mathrm{~g}\end{array}$ \\
\hline & Buckwheat Strawberry & $\begin{array}{l}\text { Buckwheat, strawberries, oat, lemon peel, fondant } \\
\text { powder, egg white, butter }\end{array}$ & $\begin{array}{l}\text { Energy: } 1596 \mathrm{~kJ} \\
\text { Carbohydrates: } 69 \mathrm{~g} \\
\text { Sugar: } 19 \mathrm{~g} \\
\text { Fat: } 8 \mathrm{~g}\end{array}$ \\
\hline & Oat Cranberry & $\begin{array}{l}\text { Oat, cranberries, hazelnuts, spelt, pumpkins seeds, } \\
\text { fondant powder, egg white, sugar }\end{array}$ & $\begin{array}{l}\text { Energy: I729 kJ } \\
\text { Carbohydrates: } 54 \mathrm{~g} \\
\text { Sugar: } 14 \mathrm{~g} \\
\text { Fat: } 19 \mathrm{~g}\end{array}$ \\
\hline
\end{tabular}


using the consensus profile method (18). This method, involved development of a consensus sensory vocabulary to describe the sensory differences in the products and an individual assessment of the snack bars on these sensory characteristics by the experts. All snack bars were produced one to three days before testing. Immediately after production, the bars were packed in boxes of $40-60$ bars in an atmosphere of 50\% pure carbon dioxide and $50 \%$ pure nitrogen. This was done to keep the bars fresh until testing.

\section{Experimental procedure}

Testing was done in classrooms during morning lessons. To familiarise the children with the testing procedure, all were given a short training session. They were introduced to the seven-point hedonic face scale (19) used to evaluate their liking of the bars with regard to the sensory modalities and to the modalities evaluated for acceptance (appearance, smell, flavour/taste, texture, overall liking). The use of the face scale was clarified by showing and exemplifying the faces in the contexts of liking of different attributes. For example; How much do you like the texture and the flavour of apples? Which smiley face corresponds to your likes/dislikes?

The children sat on their own during testing and were not disturbed by their peers. It was emphasised that there was no right or wrong answers and that we asked for each individual child's opinion.

\section{Acceptance and preference testing}

The five bars were served in randomised order and the children received no information about the composition or content of the bars. For each of the bars, the children rated their liking of the appearance, smell, flavour/taste and texture and their overall liking in that order. The seven-point hedonic face scale was used to record liking, graded from 'really bad' to 'really good'. The children were asked to indicate how much they liked the given modality by ticking the facial expression corresponding to their preferences. They also responded to whether they wanted to eat the sample again (yes, maybe, no).

After evaluating acceptance, a preference rank-order of the five bars was performed using a five-point smiley ranking test. The children were asked to rank order the bars from the most preferred to the least preferred. The children were finally given the opportunity to write individual comments about their liking of each sample.

\section{Analysis of data}

A principal component analysis (PCA) was performed in the software program Simca-P + v.11.0.0.0 (Umetrics $\mathrm{AB})$ to provide a graphical display (plot) of the bars. Hedonic ratings of each snack bar were converted into a numeric score ranging from 1 (really bad) to 7 (really good). One-way ANOVA was performed to access differences in the evaluations of the sensory modalities of the snack bars, including the ratings of overall liking and willingness to eat the bars again. Tukey's multiple comparison test was done on modalities for which significant differences in liking responses were found in the ANOVA. Pearson correlations were performed to correlate overall liking to individual liking scores of modalities in order to identify the main determinants for overall liking.

Comparisons were made between Danish and Swedish children and between boys and girls. Statistical analyses were conducted with SYSTAT version 10, SPSS Inc. 2000. The alpha criterium for significance was $p \leq 0.05$.

The Friedman's test of rank sum (20) was used to analyse the ranking test. Ranks were converted into a numeric score ranging from five (most preferred) to one (least preferred). The least significant ranked difference (LSRD) values were calculated to ascertain which of the samples were significantly preferred over the others $(p \leq 0.05)$ at the group level.

\section{Results}

The sensory attributes that characterized the five Nordic snack bars are shown as a PCA plot explaining $82 \%$ of the total variance in sensory data (Fig. 1). Results indicate there were differences between the five samples in the comparison of aroma intensity, fruit/berry odour, flavour intensity, sweetness, fruit/berry flavour, glossiness, redness, golden colour, crunchiness and particle size.

\section{Acceptance ratings}

The kamut/pumpkin and oat/cranberry bars were given the highest liking scores in both countries (Fig. 2). Around $40 \%$ of the children rated the bars in the 'really good' category. In Denmark, the rye/bilberry bar was also rated high in overall liking. However, the Swedish children rated this bar significantly lower than the Danish children $(p=0.027)$. The bars given the lowest liking scores in both countries were pumpernickel/sea buckthorn and buckwheat/strawberry. Overall, the differences in mean rating scores between countries were small. Furthermore, ratings did not differ significantly between genders. The results in the Danish and Swedish boys and girls were therefore pooled together to analyze the results of the acceptance ratings of sensory modalities.

Danish and Swedish children rated their liking of the appearance, smell, flavour/taste and texture of the kamut/pumpkin and oat/cranberry bars over the pumpernickel/sea buckthorn and rye/bilberry bars (Table 2). The rating for appearance and smell of the buckwheat/ strawberry corresponded to the bars that were more liked in the overall evaluation. However, the ratings given for the taste and texture properties of the buckwheat/ strawberry bar were significantly lower than for the bars that were more liked. The pumpernickel/sea buckthorn 


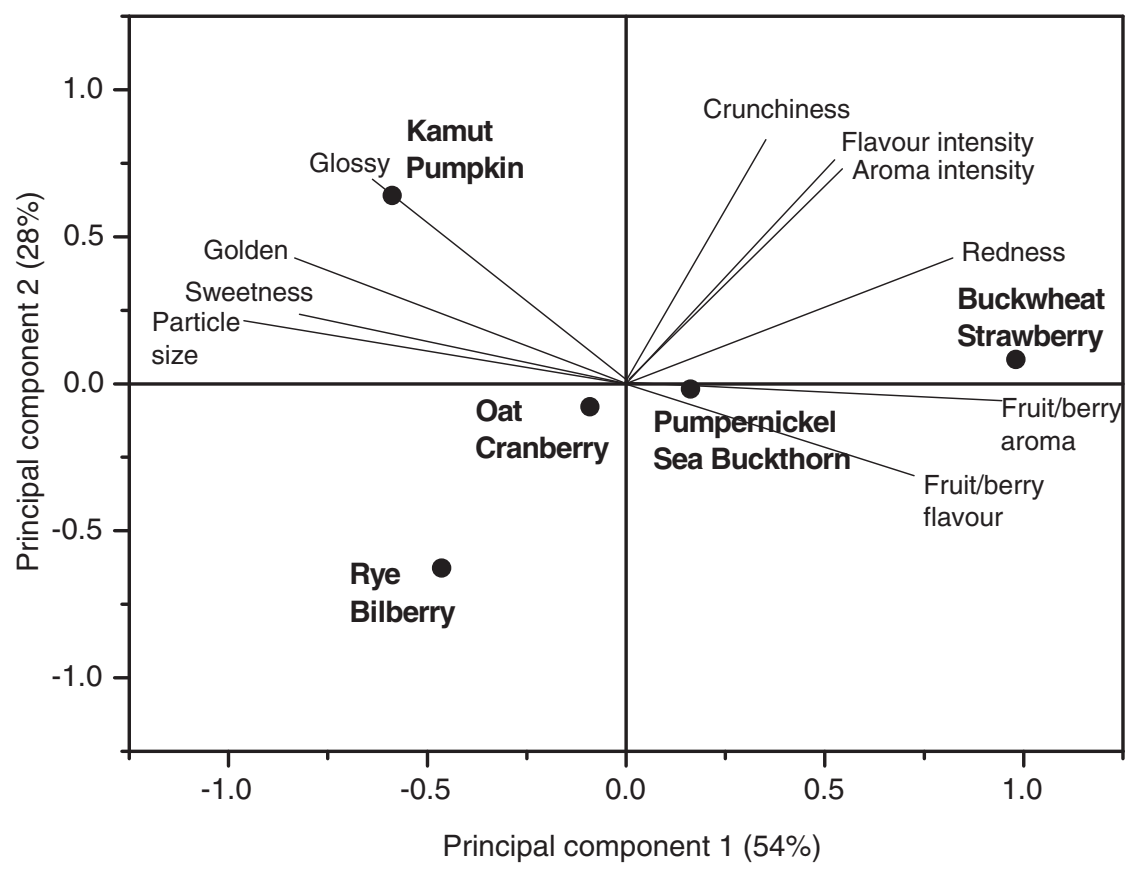

Fig. 1. PCA biplot showing the relationships between the Nordic snack bars and their most salient sensory characteristics.

bar was rated lowest for appearance, smell, flavour/taste and texture. Results are in line with children's individual comments on the bars, indicating that the most preferred samples were more tasty and familiar than the least liked sample. It should be noted that on average $10 \%$ of the children disliked ('really bad' category) all bars regardless of country and gender. The sea buckthorn bar was disliked by almost $30 \%$ of the children, confirming the above results.

It was found that all modalities had significant impact on overall liking: Flavour $r=0.88$; texture $r=0.79$; odour $r=0.62$ and appearance $r=0.56$.

\section{Preference ranking}

The oat/cranberry and kamut/pumpkin were the most preferred bars among the Danish ( $p \leq 0.05$, Table 3$)$ and the Swedish children. The pumpernickel/sea buckthorn bar was consistently ranked lowest. Danish children also preferred the rye/bilberry bar to the buckwheat/ strawberry and pumpernickel/sea buckthorn bars.

Preferences were similar among boys and girls, although some differences were found (Table 3). Danish girls preferred the buckwheat/strawberry bar to the pumpernickel/sea buckthorn bar $(p \leq 0.05)$. This was observed in neither Swedish boys and girls, nor Danish boys. Danish girls and boys and Swedish girls preferred the rye/bilberry bar to the pumpernickel/sea buckthorn bar; this was not observed among Swedish boys.

A total of 54 and $58 \%$ of the Danish and Swedish children were willing to eat the kamut/pumpkin and oat/cranberry bar again, whereas only $20 \%$ were willing to eat the less preferred pumpernickel/sea buckthorn

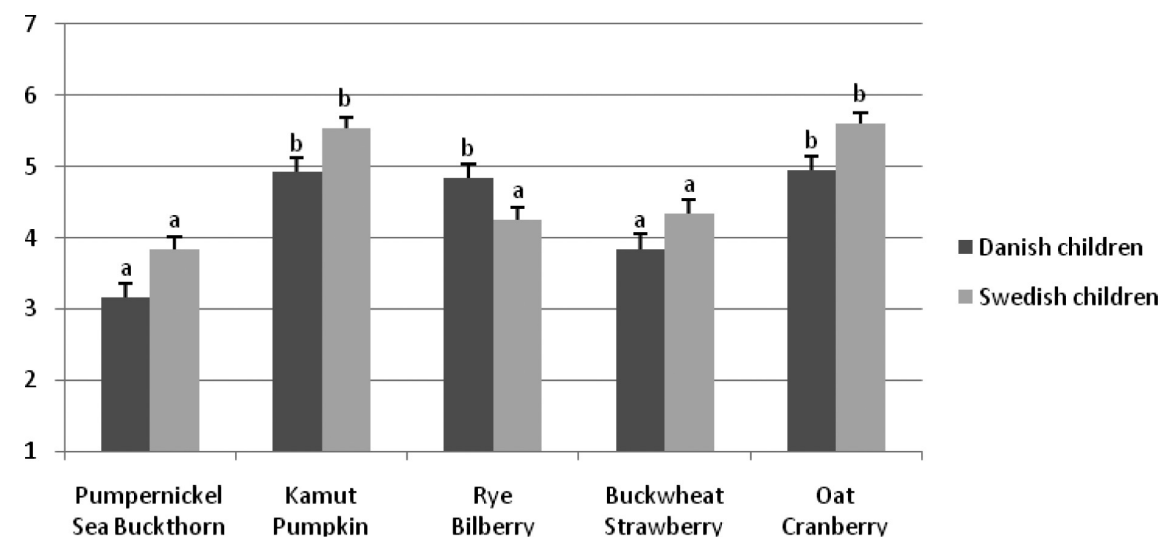

Fig. 2. Danish and Swedish children's ratings for 'overall liking' of the five snack bars. Values are mean \pm standard error means. Significant differences in overall liking ratings between bars are illustrated by a and $b$. 
Table 2. Danish and Swedish children's acceptance ratings of five Nordic snack bars. The results are presented as mean values and standard error of mean $(\mathrm{m} \pm S E M)$ and should be compared horizontally for each sensory attribute

\begin{tabular}{lccccc}
\hline Danish and Swedish children & Pumpernickel Sea Buckthorn & Kamut Pumpkin & Rye Bilberry & Buckwheat Strawberry & Oat Cranberry \\
\hline Appearance & $3.81 \pm 0.11^{\mathrm{a}}$ & $5.22 \pm 0.11^{\mathrm{b}}$ & $4.40 \pm 0.11^{\mathrm{c}}$ & $5.20 \pm 0.12^{\mathrm{b}}$ & $5.34 \pm 0.10^{\mathrm{b}}$ \\
Smell & $3.63 \pm 0.12^{\mathrm{a}}$ & $5.26 \pm 0.12^{\mathrm{b}}$ & $4.16 \pm 0.12^{\mathrm{c}}$ & $5.21 \pm 0.13^{\mathrm{b}}$ & $5.19 \pm 0.12^{\mathrm{b}}$ \\
Flavour/taste & $3.18 \pm 0.14^{\mathrm{a}}$ & $5.13 \pm 0.13^{\mathrm{b}}$ & $4.44 \pm 0.14^{\mathrm{c}}$ & $4.18 \pm 0.14^{\mathrm{c}}$ & $5.15 \pm 0.13^{\mathrm{b}}$ \\
Texture & $3.64 \pm 0.12^{\mathrm{a}}$ & $5.10 \pm 0.12^{\mathrm{b}}$ & $4.52 \pm 0.12^{\mathrm{c}}$ & $4.32 \pm 0.12^{\mathrm{c}}$ & $5.20 \pm 0.12^{\mathrm{b}}$ \\
\hline
\end{tabular}

Mean values with different letters are significantly different at $p \leq 0.05$.

bars again. Furthermore, 32 and $40 \%$ reported that they were willing to eat the buckwheat/strawberry and rye/bilberry bars again, respectively. Danish children reported a higher willingness to eat the rye/bilberry bar again compared to the Swedish children $(p=0.03)$. However, no significant differences were found in the comparison between Danish and Swedish girls and Danish and Swedish boys. Further, the ranking result did not differ significantly between the genders for any of the bars.

\section{Discussion}

The aim of this study was to examine 8-11 year-old Danish and Swedish children's acceptance of snack bars composed of Nordic ingredients. In line with our expectation, the sensory testing showed that children's acceptance and preferences for the snack bars varied according to the composition of sensory properties. Most children liked and preferred the kamut/pumpkin and oat/cranberry bars, while the pumpernickel/sea buckthorn bar was the least liked and least preferred.

Food acceptance is suggested to be determined by the perception and liking of the taste, flavour and texture of the food (21). This is in accordance with the results of the correlations showing that all modalities had significant impact on overall liking of the bars. It should be noted that flavour had highest impact on the children's overall liking score. This finding indicates that foods rated high in appearance may appeal more to children and thereby promote tasting in particular in children with high food neophobia; however, the actual flavour is the most important determinant of children's liking. The preferred kamut/pumpkin and oat/cranberry bars were liked for their appearance, smell, flavour/taste and texture. In contrast, the least preferred pumpernickel/sea buckthorn bar was disliked for all of the sensory modalities. Further, the buckwheat/strawberry bar was one of the least liked bars although the ratings for appearance and smell corresponded to the bars that were liked. The result indicates the importance of considering all of the sensory modalities in order to design acceptable food products for children.

The sensory characteristics of the bars varied in sweetness, crunchiness, fruitiness, colour and particle size. In an earlier sensory study of graham snacks, elementary school children suggested improving the snacks by making them taste sweeter and adding more colour (22). In our study, the colourful and golden snack bars (kamut/pumpkin, buckwheat/strawberry and oat/cranberry) were rated as being liked more for their appearance in comparison to samples that were darker in colour (rye/bilberry, pumpernickel/sea buckthorn). However, even if the preferred kamut bar had a sweet taste, the sweetness intensity of the bars did not seem to be a major factor that influenced children's acceptance. No significant differences were found in the liking of the sweet tasting

Table 3. Preference ranking results in Danish and Swedish children and in boys and girls, respectively. The sum of all ranks per snack bar is displayed. The results should be compared horizontally

\begin{tabular}{|c|c|c|c|c|c|}
\hline Preference ranking & Pumpernickel Sea Buckthorn & Kamut Pumpkin & Rye Bilberry & Buckwheat Strawberry & Oat Cranberry \\
\hline \multicolumn{6}{|l|}{ Danish children } \\
\hline Boys \& Girls & $278^{\mathrm{a}}$ & $491^{\mathrm{b}}$ & $422^{\mathrm{c}}$ & $331^{d}$ & $488^{\mathrm{b}}$ \\
\hline Boys & $152^{\mathrm{a}}$ & $238^{\mathrm{b}}$ & $204^{\mathrm{b}}$ & $|6|^{\mathrm{a}}$ & $235^{\mathrm{b}}$ \\
\hline Girls & $126^{\mathrm{a}}$ & $253^{\mathrm{b}}$ & $218^{\mathrm{b}}$ & $170^{c}$ & $253^{\mathrm{b}}$ \\
\hline \multicolumn{6}{|l|}{ Swedish children } \\
\hline Boys \& Girls & $222^{\mathrm{a}}$ & $415^{b}$ & $278^{c}$ & $266^{\mathrm{ac}}$ & $424^{\mathrm{b}}$ \\
\hline Boys & $095^{\mathrm{a}}$ & $175^{\mathrm{b}}$ & $110^{\mathrm{a}}$ & $120^{\mathrm{a}}$ & $160^{\mathrm{b}}$ \\
\hline Girls & $127^{\mathrm{a}}$ & $240^{\mathrm{b}}$ & $168^{c}$ & $146^{\mathrm{ac}}$ & $264^{\mathrm{b}}$ \\
\hline
\end{tabular}

Values with different letters are significantly different at $p \leq 0.05$. 
rye/bilberry and the less sweet buckwheat/strawberry. Further, the less sweet tasting buckwheat/strawberry was rated significantly higher in liking compared to the pumpernickel/sea buckthorn.

The most liked and preferred snack bars were given descriptions such as 'popcorn-like' and 'like breakfast cereals' (kamut/pumpkin), and 'it has a lot of nuts' (oat/cranberry). The least liked and least preferred pumpernickel/sea buckthorn bar was described as having a 'strange taste' and 'the raisins do not taste like they usually do'. One of the main ingredients in this bar, the sea buckthorn berry, has previously been described as having a unique strong flavour and a sour taste (23). The flavour of the berry might have been unfamiliar to the children and thus influencing their liking of this bar. The children also commented negatively on the snacks bars if they recognized an ingredient they did not like, e.g. 'I do not like the taste of rye bread' (pumpernickel/ sea buckthorn; rye/blueberry). This result agrees with earlier studies that identified the taste of whole grain as a barrier to gaining children's acceptance of whole grain products $(24,25)$.

Similar results in the overall evaluation of the Nordic snack bars were observed in Denmark and Sweden. However, a greater variation was expected from the two countries because of the different organisation and exposure at school meals (5). Previous cross-cultural studies of food choices have found that familiarity is important for the consumer's preferences (26). The similar results for Danish and Swedish children's snack bars preferences could be related to their familiarity and expectations of snack foods, however.

Recent reports on Danish and Swedish school children's snacking patterns have revealed relatively high intakes of cake, candy, fast food, and juice (6-9). These are foods whose intake is recommended to be reduced because of their high content of sugar and saturated fat, providing a great deal of energy but few nutrients (14). The Nordic snack bars were sweetened with honey and sugar. However, since the bars were also composed of several nutritious ingredients (e.g. dietary fibres, minerals and antioxidants), they can be considered preferable over most of the snack foods that the children usually prefer. The children's acceptance of the Nordic ingredients also implied that they might be used in a variety of food products. Foods mainly originating from Nordic countries have been shown to offer several health benefits $(15,17)$. In particular, whole grains are suggested to improve diet quality among children (27) and to reduce the risk of coronary heart diseases in future (28).

\section{Methodological considerations}

The children were consistent in their ratings and ranking preferences. Hence, the methodology appeared to fit well with the children's cognitive capacity, although some of the youngest children ( 8 years) had difficulty complying with the guidelines and refused to taste some of the bars. A limitation of the study was that Swedish boys were under represented in relation to Swedish and Danish girls and Danish boys. This might have affected the statistical comparisons between genders. Another limitation was that the Nordic snack bars were evaluated in structured tasting sessions. In a 'real life situation', many factors influence food choices and food preferences, such as the packaging of the product (29), the social setting (30) and appetite (3). The results were furthermore connected with the children's initial liking of the products. Previous studies have consistently observed that liking of novel initially disliked foods increases after repeated consumption due to increased familiarity $(31,32)$. This was also observed in an exposure study where the disliked sea buckthorn bar was tested against the liked kamut bar (33). Liking of the sea buckthorn bar increased across exposures while it was constant for the already liked kamut bar. These findings highlight the importance of presenting foods to children over and over again, even though their initial acceptance is low. Future studies may also focus on how the Nordic ingredients can be used in a variety of food products in order to expand the market of more healthy food alternatives for children.

\section{Conclusions}

Danish and Swedish children's acceptances and preferences for five Nordic snacks bars varying in composition of whole grains, nuts and berries were highly influenced by the sensory characteristics of the bars. Flavour was the main determinant of the children's overall liking of the bars followed by texture, odour and appearance. In line with earlier studies, the novel food ingredients seemed to influence the children's preferences. The Nordic snack bars may have a potential to be a snack option for Danish and Swedish school children, but repeated exposures to the products are recommended to increase children's acceptance.

\section{Acknowledgements}

We thank all the schools, teachers and children who participated in the study. Furthermore, we acknowledge Meyers Madhus for developing the snack bars and Karin Hess Ygil, the Technical University of Denmark (DTU), for calculating the energy content and macronutrient distribution of the bars. The study is part of the OPUS project 'Optimal well-being, development and health for Danish children through a healthy New Nordic Diet' supported by a grant from the Nordea Foundation.

\section{Conflict of interest and funding}

The authors have not received any funding or benefits from industry to conduct this study. 


\section{References}

1. Nicklaus S, Boggio V, Chabanet $\mathrm{C}$, Issanchou $\mathrm{S}$. A prospective study of food preferences in childhood. Food Qual Prefer 2004; 15: $805-18$

2. Pliner P, Stallberg-White C. Pass the ketchup please; familiar flavors increase children's willingness to taste novel foods. Appetite 2000; 34: 95-103.

3. Shepherd R. Social determinants of food choice. Proc Nutr Soc 1999; 58: 807-12.

4. Mäkelä J, Kjærnes U, Pipping Ekström M, Lórange Fürst E, Gronow J, Holm L. Nordic meals: Methodological notes on a comparative survey. Appetite 1999; 32: 73-9.

5. Johansson B, Mäkelä $J$, Roos $G$, Hillén $S$, Hansen GL, Jensen TM, et al. Nordic children's foodscapes: Images and reflections. Cult Soc: Int J Multidiscipl Res 2009; 12: 25-51.

6. Husby I, Heitmann BL, Jensen K. Meals and snacks from the child's perspective: the contribution of qualitative methods to the development of dietary interventions. Public Health Nutr 2009; 12: 739-47.

7. Enghardt Barbieri H, Pearson M, Becker W. Riksmaten - barn 2003, Livsmedels-och näringsintag bland barn i Sverige [National food - children 2003, Dietary habits and nutrient intake in Swedish children]. Uppsala: Livsmedelsverket; 2003.

8. Hoppe C, Biltoft-Jensen A, Trolle E, Tetens I. Beskrivelse af 8- til 10-årige og 12- til 14-årige børns kost - med fokus på indtag i skole og fritidsordning, OPUS rapport [Description of 8 to 10 year old and 12 to 14 year old children's diet focusing on intakes during school time and after school care, An OPUS report]. Søborg: The Technical University Denmark; 2009.

9. Patterson E, Wärnberg J, Kearney J, Sjöström M. Sources of saturated fat and sucrose in the diets of Swedish children and adolescents in European Youth Heart Study: strategies for improving intakes. Public Health Nutr 2010; 13: 1955-64.

10. Ebbeling CB, Pawlak DB, Ludwig DS. Childhood obesity: public-health crisis common sense cure. Lancet 2002; 360: 473-82.

11. WHO. Global strategy on diet physical activity and health. Geneva: WHO; 2004: Available from http://www.who.int/ dietphysicalactivity/strategy/eb11344/strategy_english_web.pdf [cited 7 December 2010].

12. Burgess Champoux T, Marquart L, Vicker Z, Ricks M. Perceptions of children parents and teachers regarding wholegrain foods and implications for a school-based intervention. Nutr Educ Behav 2006; 38: 230-7.

13. Haerens I, De Bourdeaudhuij G, Barba G, Eiben J, Fernandez A, Hebestreit E, et al. Developing the IDEFICS community-based intervention program to enhance eating behaviors in 2- to 8-year-old children: findings from focus groups with children and parents. Health Educ Res 2009; 24: 381-91.

14. Nordic Council. Nordic Nutrition Recommendations 2004 Integrating nutrition and physical activity, 4th ed. Copenhagen: Nordic Council of Ministers; 2004.

15. Adamsson V, Reumark A, Fredriksson I, Hammarström E, Vessby B, Johansson G, et al. Effects of a healthy Nordic diet on cardiovascular risk factors in hypercholesterolaemic subjects: a randomised controlled trial (NORDIET). J Intern Med 2011; 269: $150-9$.

16. Bere E, Brug J. Towards health-promoting and environmentally friendly region-al diets - a Nordic example. Public Health Nutr 2008; 14: $1-6$.

17. Mithril C, Dragsted LO, Meyer C, Blauert E, Holt MK, Astrup A. Guidelines for the New Nordic Diet. Public Health Nutr 2012; 642-649. DOI:10.1017/S136898001100351X
18. Pages J. Collection and analysis of perceived product interdistances using multiple factor analysis: Application to the study of 10 white wines from Loire Valley. Food Qual Prefer 2005; 16: 642-9.

19. Guinard JX. Sensory and consumer testing with children. Trends Food Sci Technol 2001; 11: 273-83.

20. Lawless HT, Heymann H. Sensory evaluation of food principles and practices, 2nd ed. New York, NY: Springer; 2010.

21. Cardello AV, Schutz H, Snow C, Lesher L. Predictors of food acceptance consumption and satisfaction in specific eating situations. Food Qual Prefer 2000; 11: 201-16.

22. Sadeghi L, Marquart LF. Consumption of graham snacks in after-school snack programs based on whole grain flour content. Br Food J 2010; 112: 273-736.

23. Titinen KM, Hakala MM, Kallio HP. Quality components of sea Buckthorn (Hippophe rhamnoides) varieties. J Agric Food Chem 2005; 53: 1692-9.

24. Delk J, Vickers Z. Determining a series of whole wheat difference thresholds for use in a gradual adjustment intervention to improve children's liking of whole-wheat bread rolls. J Sensory Stud 2007; 22: 639-52.

25. Berg C, Jonsson I, Conner M, Lissner L. Perceptions and reasons for choice of fat- and fibre-containing foods by Swedish school children. Appetite 2003; 40: 61-7.

26. Pages J, Bertrand C, Ali R, Husson F, Le S. Sensory analysis comparison of eight biscuits by French and Pakistani panels. J Sensory Stud 2007; 22: 665-86.

27. O'Neil CE, Nicklas TA, Zanovec M, Cho S, Kleinman R. Consumption of whole grains is associated with improved diet quality and nutrition intake in children and adolescents: the national Health and Nutrition Examination Survey 1999-2004. Public Health Nutr 2011; 14: 347-55.

28. Harris KA, Kris-Etherton P M. Effects of whole grains on coronary heart disease risk. Curr Athereroscler Rep 2010; 12: $368-76$.

29. Ogba EE, Johnson R. How packaging affects the product preferences of children and the buyer behaviour of their parents in the food industry. Young Consumers 2010; 11: 77-89.

30. Prim M, Gustafsson IB, Hall G. The impact of the meal situation on the consumption of ready meals. Int $\mathbf{J}$ Consumer Stud 2005; 29: 485-92.

31. Lakkakula A, Geaghan J, Zanovec M, Perce S, Tuuri G. Repeated taste exposure increase liking for vegetables by low-income elementary school children. Appetite 2010; 55: $226-31$.

32. Wardle J, Herrera ML, Cooke L, Gibson EL. Modifying children's food preferences: the effects of exposure and reward on acceptance of an unfamiliar vegetable. Eur J Clin Nutr 2003; 57: $341-8$.

33. Hausner H, Hartvig D, Reinbach H, Wendin K, Bredie W. Effects of repeated exposure on acceptance of initially disliked and liked Nordic snack bars in 9 to 11 year-old children. Clin Nutr 2012; 31: 137-43.

\footnotetext{
*Karin Wendin

Department of Food Science

University of Copenhagen

Rolighedsvej 30

DK-1958 Frederiksberg

Denmark

Tel: +46708380740

Fax: +4646 I88 765

Email: Kawe@life.ku.dk
} 